\title{
¿SUEÑAN LOS ESCRITORES CON MECENAS DESAHUCIADOS? UNA conversación entre Roberto Bolaño y Ricardo Piglia
}

\author{
Jacobo Arango ${ }^{1}$ \\ Universidad del Valle, Colombia.
}

\begin{abstract}
Resumen: El siguiente ensayo analiza un diálogo entre los escritores latinoamericanos Roberto Bolaño y Ricardo Piglia que sucedió en 2001 por correo electrónico. Ambos escritores han construido una sólida figura de autor que, en muchos sentidos, trasciende el espacio ficcional. A pesar de que también comparten puntos de vista sobre los problemas que enfrenta la literatura latinoamericana contemporánea, este ensayo intenta mostrar algunas diferencias clave que suelen pasarse por alto. Finalmente, leemos otros textos breves (ensayos como "Sevilla me mata" o "Derivas de la pesada" y entrevistas dadas por Piglia) que ubican dicho diálogo en un contexto más amplio.
\end{abstract}

Palabras clave: Bolaño; figura de autor; literatura latinoamericana contemporánea; Piglia.

Recibido: 19 de agosto de 2019

Aprobado: 29 de octubre de 2019

\section{Do writers dream with terminally ill patrons? A conversation between Roberto Bolaño and Ricardo Piglia}

\begin{abstract}
The following essay analyzes a dialogue between Latin American writers Roberto Bolaño and Ricardo Piglia that took place in 2001 by email. Both writers have built a strong author figure that, in many ways, transcends the fictional space. Although they also share views about the issues that the contemporary Latin American literature faces, this essay attempts to show some key differences that are often overlooked. Finally, we read other short texts (essays like "Sevilla me mata" or "Derivas de la pesada" and interviews given by Piglia) that place this dialogue in a broader context.
\end{abstract}

Keywords: Author figure; Bolaño; contemporary Latin American literature; Piglia.

\footnotetext{
${ }^{1}$ Licenciado en Literatura y candidato a Magíster en Literaturas Colombiana y Latinoamericana de la Universidad del Valle. Su campo de investigación actual es la literatura argentina contemporánea. Correo electrónico: jarango2826@gmail.com
} 
¿Por qué Piglia no se enamoró de Gombrowicz y sí de Arlt? Roberto Bolaño. Entre paréntesis.

En marzo de 2001, el suplemento Babelia del diario español El País publicó un diálogo por correo electrónico entre Ricardo Piglia y Roberto Bolaño. Me parece que este pequeño acontecimiento, no muy revisado por la crítica contemporánea, es un buen punto de partida para analizar dos poéticas que se distancian, cada una a su manera, de ciertos estereotipos propios del escritor latinoamericano contemporáneo (según veremos más adelante) y, lo más importante, el punto definitivo de este trabajo, que se enfrentan y contradicen entre sí. Para alcanzar este objetivo es necesario, en primer término, contextualizar esas voces en el momento particular en que se encuentran por primera vez. Posteriormente, veremos con detalle unas cuantas escenas de dicho diálogo, con el fin de esbozar una serie de puntos de contacto (las listas de Bolaño, la característica manera que tiene Piglia de reconocer a otros escritores de su época, por ejemplo), así como ciertos desencuentros que pasan desapercibidos en una primera lectura. Por último, se exponen algunas consideraciones sobre las marcas más visibles de ese distanciamiento, tal y como aparecen en otras obras de los autores.

¿Cómo llegan a este encuentro? A principios de 2001 Bolaño era ya un autor consagrado, sobre la estela de los premios Herralde y Rómulo Gallegos obtenidos en 1999. Su editorial, consciente del extraño fenómeno de ventas y crítica que tenía entre manos, se las arreglaba para publicar al menos un libro suyo por año. Lo extraordinario de este momento álgido es que Bolaño, arrojado al torbellino de los escándalos (véase el caso Eltit, o lo que suscita su breve visita a Chile, también en 1999 y consignada en Entre paréntesis (2004), obra vital para mi análisis) y el aplauso desmedido, eligió reafirmar $-\mathrm{o}$, si es posible, ir aún más lejos- la figura de escritor que había construido. Un perfil fácil de identificar; la nariz fuerte, las cejas pobladas, las gafas de cristal fino, el cabello revuelto, la chaqueta de cuero, el cigarrillo sempiterno. El inmigrante en tránsito perpetuo, sin educación formal, el poeta aquí de la mendicidad y el cirujeo en las veredas, diría Fogwill, el cazador de premios-búfalo, el self-made man, el latinoamericano irredento. El escritor que tiene un doble, una autobiografía apócrifa, un canon 
bien definido (Borges, Cortázar, Nicanor Parra). También era, como ha observado Jorge Volpi en El insomnio de Bolívar (2009), en extremo consciente "de su lugar en la literatura mundial, y en especial la latinoamericana (...); cada uno de sus textos es una respuesta -valdría la pena decir: una bofetada- a la tradición, o más bien a las tradiciones que lo obsesionaban." (173)

¿Cuánto de esto se puede aplicar al mismo Piglia? No es necesario hacer una enumeración exhaustiva para entender que éste, sobre todo en su primera etapa, también reconoce la importancia de construir otro lugar de acercamiento, de resistir al influjo de los epígonos. La siguiente cita de Los diarios de Emilio Renzi: los años felices (2016) sirve para confirmar que se trata de un propósito compartido, otra señal que realza sus figuras en oposición a la, en ocasiones única, frecuencia en que más se leyó la literatura latinoamericana durante el siglo XX.

Está claro que para sobrevivir al boom hay que mantenerse apartado. Quedarse quieto, escribir relatos a contramano de la expansión que lidera la literatura latinoamericana actual. Escribir sin interesarse por la circulación (nunca pasaré de los tres mil ejemplares, con suerte). Menos es más. Esperar. El que pueda mantener la calma en medio de la avalancha llegará más lejos, sin quemarse en el camino. Habrá que ver. (106)

Una posición que suscribiría el mismo Bolaño, como queda claro si se revisan la mayoría de los textos e intervenciones compiladas en Entre paréntesis (2004) o El gaucho insufrible (2003). Pero los que conversan por primera vez en 2001 no son jóvenes imberbes al margen de la gran industria cultural hispanoamericana. El tiempo ha transcurrido (aquí cabe anotar que estos autores, como la mayoría de los pertenecientes a la generación de mitad del siglo XX, a menudo escriben para saldar deudas con un pasado hostil, según vemos en Amuleto (1999) y, sobre todo, en el ensayo "Ernesto Guevara, rastros de lectura") y las condiciones materiales de su escritura también son otras. Así lo señala el chileno en su primera intervención, que da inicio al diálogo:

Querido Piglia, ¿te parece bien si empezamos hablando de algo que dices en La novela polaca? “¿Cómo hacer callar a los epígonos? (Para escapar a veces es preciso cambiar de lengua)". Tengo la impresión de 
que en los últimos veinte años, desde mediados de los setenta hasta principios de los noventa y, por supuesto, durante la nefasta década de los ochenta, este deseo es algo presente en algunos escritores latinoamericanos y que expresa básicamente no una ambición literaria sino un estado espiritual de camino clausurado. Hemos llegado al final del camino (en calidad de lectores, y esto es necesario recalcarlo) y ante nosotros (en calidad de escritores) se abre un abismo. (Bolaño párr. 2)

La cita que hace Bolaño pertenece a Formas breves (2000), el primer libro que Piglia edita con Anagrama y, por consiguiente, su aparición definitiva ante el público hispanoamericano. Cabe recordar que, en este instante, el argentino no tiene un solo premio internacional que afiance su posición en el mercado. Es uno más, como se dice en "Sevilla me mata" (discurso incluido en Entre paréntesis), del "grupo lamentable de treintañeros y cuarentañeros y uno que otro cincuentañero esperando a Godot, que en este caso es el Nobel, el Rulfo, el Cervantes, el Príncipe de Asturias, el Rómulo Gallegos." (Bolaño, 312) Quizá esto sirva para entender una diferencia particular que se manifiesta a partir de la citada intervención del chileno. Él ha cruzado un umbral decisivo; muerto Donoso, nadie puede oponerse a su rápida e inesperada conquista de un espacio central en la tradición de su país, a la que siempre cuestiona con su habitual registro cáustico: "La literatura chilena, tan prestigiosa en Chile, no tiene más de cinco nombres válidos, eso hay que recordarlo como ejercicio crítico y autocrítico." (Bolaño 104)

En cambio, Piglia enfrenta varias vicisitudes. Recién salido de la gran polémica ocasionada por el Premio Planeta Argentina 1997 (saldada en 2005 tras un humillante fallo de la Corte Suprema que lo obligó, junto a la editorial, a resarcir al demandante, Gustavo Nielsen, uno de los finalistas de dicho galardón), que acelera considerablemente su desembarco en España, su mayor virtud es que ha sobrevivido. Aún hay más. Dos de los escritores más reconocidos de su país (Fogwill y Aira) se oponen, junto a Beatriz Sarlo, acaso la crítica más importante de América Latina, a su proyecto. Ésta, por cierto, trabaja de manera activa por imponer el valor de la poética de Saer, a quien enfrenta con Piglia en la nota "Ficciones del saber", incluida en sus Escritos sobre literatura argentina (2007):

De los libros de Juan José Saer, aparecidos entre 1960 y 1967, se 
habrán vendido algunos miles de ejemplares, pocos más que de las tres ediciones de Respiración artificial. (...) A la literatura de Saer nadie la esperaba. La novela de Piglia demostró inmediatamente después de aparecer en 1980 que allí estaban los lectores o, en todo caso, que la novela podía producirlos. Saer más bien demostró lo contrario: escribía ficciones que no podían encontrar ni producir su público. (356)

Sin duda, se trata de un panorama difícil para cualquier escritor. Mientras Bolaño habla seguro, consciente de que ha cruzado un umbral definitivo y está, por fin, al otro lado de las comparaciones maliciosas (con el Boom o sus contemporáneos, digamos) y los juicios de valor, el camino del siglo XX para el Piglia escritor o lector, tanto da, está lejos de ser clausurado. Quizá por eso no responde la pregunta y plantea un desvío, porque para él se trata precisamente de lo opuesto, de ir cada vez más hacia atrás. Su respuesta, de la que nos ocuparemos en breve, ilumina esta cuestión y abre un plano nuevo entre ambos en el que vale la pena detenerse:

Por otro lado, no sé si la situación que describes pertenece exclusivamente a los escritores llamados latinoamericanos. Tal vez en eso estamos más cerca de otras tentativas y de otros estilos no necesariamente latinoamericanos, moviéndonos por otros territorios. Porque lo que suele llamarse latinoamericano se define por una suerte de anti-intelectualismo, que tiende a simplificarlo todo y a lo que muchos de nosotros nos resistimos. He visto esa resistencia con toda claridad en tus libros, y también en los de otros como DeLillo o Magris, que escriben en otras lenguas. (...) Entonces, ¿seguimos siendo latinoamericanos? (Piglia, párr. 3, la cursiva es mía)

\section{Reconocimientos/Una política del nombre}

Un escritor define su poética en contra de otras. Ricardo Piglia. Las tres vanguardias.

Es toda una señal que Las tres vanguardias (2016), uno de los últimos libros que Piglia publica en vida, ofrezca como revelaciones, como ejemplos de una literatura sincronizada con los grandes debates modernos, a Saer, Puig, y Walsh, que nacen respectivamente en 1937, 
1932 y 1927. No hablo aquí de la pertinencia o valor de estos autores, sino de la temporalidad. En el fondo se trata de eso, de dilatar los reordenamientos canónicos, de cerrar la puerta (mejor, de intentarlo con un libro) a los jóvenes y no tanto que están a punto de echarla abajo. Estacionado en los años setenta, Piglia es fiel a los debates que su generación produjo (¿Arlt o Borges?) y a las voces que lo formaron. Para todos los efectos, el único autor joven, si se lo puede llamar así, que aparece como invitado en los ciclos que ofrece en la TV pública es German Maggiori (Borges, por Piglia, segunda clase, septiembre 14 de 2013), su sobrino, en un gesto que replica la famosa frase de Respiración artificial sobre la manera familiar en que se transmite la tradición literaria.

Por supuesto, estas tácticas no hacen parte del programa de Bolaño, que se autoproclama como divulgador de la nueva literatura latinoamericana. Ahí está Entre paréntesis (2004), compilación de columnas, textos breves y entrevistas que también incluye una suerte de canon portátil, iniciativa similar a la adelantada por la versión en castellano de la revista Granta y que los ciclos tipo Bogotá 39, al igual que la lista que Volpi incluye en El insomnio de Bolívar imitarán años después. Hay una fuerte marca en ese libro póstumo: Bolaño todo el tiempo está presentando en elogiosos términos a un variado número de intelectuales y escritores. He aquí una breve serie, que pone de manifiesto también el carácter latinoamericano del elogio. Sobra decir que no incluyo los previsibles reconocimientos a Fresán, A.G. Porta o Mario Santiago, amigos célebres:

...Domingo Miliani, que para mí encarna la figura canónica del intelectual latinoamericano, que lo ha leído todo y que lo ha vivido todo y que encima de todo es bueno. (...) Miliani pertenece a una generación que es patrimonio de todos nosotros. Para los latinoamericanos es un lujo, y digo lujo sabiendo muy bien lo que digo, tener hombres así. (31)

Una de mis pocas intuiciones es Rodrigo Pinto. No creo que en Chile haya muchos críticos como él. Su persona es impagable: cada poro de Rodrigo Pinto nos está hablando de su amor por la literatura, de 
su humor, de su sabiduría. Rodrigo Pinto es el chileno mítico, aquel que lo ha leído todo o que está dispuesto a leerlo todo. (67)

... la fuerza de Bayly como narrador, la fuerza como dialoguista, la capacidad de Bayly para salir de cualquier atolladero, es extraordinaria. Cualquier escritor se daría por satisfecho con eso. (...) a Bayly hay que exigirle lo que él ya nos da: el oído más portentoso de la nueva narrativa en español... (305)

Después de un tiempo, como anotó Gonzalo Garcés en "La autobiografía de Bolaño", el lector atento percibe que

....al hablar de ellos Bolaño a menudo es vago. Al cabo de un tiempo el entusiasmo parece ceder a la fórmula: "Uno de los mejores narradores", "sabe asomarse al abismo", "se adentra en la oscuridad con los ojos abiertos", sobre demasiados dice lo mismo y en el mismo tono. (párr. 8)

No obstante, a diferencia de los reconocimientos que Piglia vacila en hacer y, en especial, de los que si hace, todavía es posible entender esas presentaciones desmesuradas como un acto gratuito, desinteresado. Bolaño elogia sin distinguir nacionalidad, género literario, temáticas o sellos editoriales. Lo hace porque comprende que debe existir, que está bien que exista, la escritura de Lina Meruane, de un Alberto Fuguet, un Daniel Sada, siempre y cuando estos nombres, miles más, tengan como punto en común la calidad literaria. Es el valor, no la política, la academia o los vínculos familiares, como bien demuestra su propia historia, el único salvoconducto importante.

Por otro lado, sabemos que la cita y el nombre son, en Piglia, una demostración -quizá la más importante- de fuerza, un acontecimiento estratégico, no una delicadeza o un gesto de amabilidad. Esto es así porque desde el principio su trabajo, en cualquier ámbito, es parte de una pesquisa, una investigación sobre las marcas particulares (véase "Notas sobre literatura en un Diario", includo en Formas breves, donde aísla los signos de la forma de la novela "obra maestra" como evidencia) que confirman y consagran a un escritor; los "modos de producción de la gloria" de Brecht, que él tanto cita. La famosa frase de Lamborghini 
("Primero publicar, después escribir") encuentra en este caso el sentido y el pulso de una decisión inquebrantable. ¿Escribir para quién? Esa es una pregunta que complejiza el análisis respetuoso de lo que conocemos como el proyecto literario de Piglia. Y es también una pregunta que marca, por si fuese necesaria una última clave, la grieta profunda entre los dos autores que nos ocupan, a menudo comparados entre sí. Yo sostengo que en esa comparación ya está implícita la necesidad de normalizarlos, ¿no?, de negar su especificidad, aquello contra lo que, de hecho, el chileno trabajó incesantemente, como veremos.

A estas maneras antagónicas de concebir la relación con los contemporáneos se puede acercar la descripción que Bolaño realiza en "Los mitos de Chtulhu", incluido en El gaucho insufrible, de aquella delicada especie conocida como el escritor cortesano:

Son rubios y morenos hijos del pueblo de Madrid, son gente de clase media baja que espera terminar sus días en la clase media alta. No rechazan la respetabilidad. La buscan desesperadamente. Para llegar a ella tienen que transpirar mucho. Firmar libros, sonreír, viajar a lugares desconocidos, sonreír, hacer de payaso en los programas del corazón, sonreír mucho, sobre todo no morder la mano que les da de comer, asistir a ferias de libros y contestar de buen talante las preguntas más cretinas, sonreír en las peores situaciones, poner cara de inteligentes, controlar el crecimiento demográfico, dar siempre las gracias. (172)

Por supuesto, Piglia no es un escritor cortesano, entre otras razones porque, como dijo alguna vez Juana Bignozzi, si fuera cierto tendría que haber llegado antes. Hay una lección ética sobre cómo ser un escritor que está condensada en su obra: en el Tardewski de Respiración artificial, en el Renzi de Plata quemada, en la Ida Brown de El camino de Ida. Su divisa, quizá, podría ser la que propone en la primera charla de su ciclo sobre Borges (2013) tras señalar que éste publicaba tanto en El hogar como en Sur o La Nación:

Es decir, iba a donde fuera a decir lo de él. Otra lección. Por eso estoy acá yo. Uno puede ir a cualquier lado si va a decir lo que tiene que decir. Si no va a decir lo que en ese lugar, imaginariamente, se supone, que uno tendría que decir. (Piglia, la cursiva es mía) ${ }^{2}$

${ }^{2}$ Ver https://www.youtube.com/watch?v=m3htEzn1BIc, minuto 3:48 en adelante. 
¿No es ésa también la posición de Bolaño? ¿Hay -puede habercontradicciones en la figura de autor? Hasta ahora he intentado sugerir algunas hipótesis que aclaren la situación particular en la que tiene lugar el diálogo. Decíamos que éste, con sus listas, sus premios recientes y su mordacidad, llegaba a 2001 en estado de gracia. El elogio a unos, el ataque a otros (casi siempre por mención directa), está, como con casi todo cuando se trata del chileno, al descubierto, ineludible. Parece que no tuviera secretos, tal es la consistencia en el tono entre su escritura de ficción y su escritura "crítica". Las invectivas que aparecen en Amuleto o Los detectives salvajes son, en más de una ocasión, reiteradas por el Bolaño que escribe artículos y ensayos o por el que contesta entrevistas. Se podría decir que no hay mediación, al menos en este aspecto, entre ambos planos, sino una concordancia fluida.

Lo opuesto, una vez más, sucede con Piglia, y podemos cerrar por ahora esta sección regresando a ese "muchos de nosotros" que emplea en su respuesta a la primera pregunta de Bolaño, ya citada. Según consigna Crítica y ficción (aunque aparece por primera vez en 1986 y tiene al menos dos reediciones más, cito aquí la de 2001), su obra más importante, en 1979 el diario argentino La Opinión publica un texto breve titulado "Sobre Sur", que responde a una encuesta sobre el legado y, si existe, la influencia de la célebre revista en los escritores argentinos. Cito aquí el último párrafo de ese texto, en el que Piglia ve a dicha publicación como un rezago de la tendencia al europeísmo que dominaba la literatura nacional durante el siglo XIX:

Toda élite se autodesigna, pero en este caso se trata además de asegurar la sucesión: los herederos debían establecer y mantener la continuidad de esa tradición exclusiva. No parece que la literatura argentina haya acatado esos pronósticos. Algunos, por supuesto, deploran este desvío; otros (entre los que me cuento) piensan que nuestra mejor literatura se ha construido, justamente, en el esfuerzo de evitar esas ilusiones. (Crítica 72, la cursiva es mía)

"Algunos" y "otros"; esa es la gran tensión que atraviesa la mayoría de los ensayos, entrevistas o cuestionarios de Crítica y ficción. El tímido paréntesis "(entre los que me cuento)" delata también el acercamiento incipiente de Piglia, en 1979, a la palabra clave que aparecerá con 
mayor énfasis en las siguientes versiones del libro. "Ficción y política en la literatura argentina", discurso pronunciado en Yale en 1987 (y, por tanto, posterior a la primera edición) representa el nacimiento de otro registro, una marca renovada de autoridad;

Arlt, Marechal, Borges: todos cruzan por la tranquera utópica de Macedonio.

Muchos de nosotros vemos ahí nuestra verdadera tradición. Pensamos también que en esos textos se abre una manera distinta de ver las relaciones entre política y literatura. Para muchos de nosotros, quiero decir, Macedonio Fernández (y no Manuel Gálvez) es el gran novelista social. (Crítica 122-123)

El plural de modestia, en teoría, funciona para que el orador comparta la responsabilidad de sus palabras con otros y generalmente se percibe como ligado al pudor. Yo afirmo que la palabra "nosotros", en la voz de Ricardo Piglia, representa todo lo contrario. ¿De quiénes habla? No conozco entrevistador que se lo haya preguntado. El paso al "nosotros" implica una toma de posesión simbólica del debate; no es lo mismo decir "Me parece que Macedonio Fernández es el gran novelista social" a presentar un consenso. Menos aún si el escenario es la Universidad de Yale. Funciona, de una manera mucho más elegante, igual que las listas de escritores contemporáneos compuestas por Bolaño (omito la relación de los nombres incluidos por considerarlo irrelevante). Por supuesto, esa palabra abre camino también a una pregunta difícil, planteada al inicio de este primer punto a debatir: ¿para quién escribió Piglia? Habría que rastrear la ubicuidad del "nosotros", la manera en que aparece siempre cuando la conversación se acerca a la literatura argentina: "Nosotros valoramos mucho que Cortázar le haya dado ese lugar importante a la novela de Leopoldo Marechal." (Sánchez, párr. 6), responde a una periodista respecto a los 50 años de Rayuela. Es la retórica de un vocero, del representante de un orden establecido. Si releemos estos signos, ¿cambia la manera en que comprendemos "Toda élite se autodesigna", esa frase de 1976 consignada en "Sobre Sur"? Oculto bajo la avalancha del boom, Piglia urde una trama que lo justifica y lo entroniza, una ficción que sólo tendrá presencia en la realidad con la llegada del lejano porvenir. "Un circuito de amigos sostiene la escritura" (10), se lee en 
Por un relato futuro: conversaciones con Juan José Saer (2015). Llegar a decir "nosotros" implica un triunfo decisivo en la carrera de Piglia.

Es el nombre del otro lo que está en juego. Nombrarlo, hacerlo decir, darle entidad. Piglia jamás va a citar una frase cualquiera de ningún texto de Bolaño. He tratado de adentrarme, hasta aquí, en dos maneras opuestas de trabajar, sin que sea necesario el término, la tradición privada, en ciertas tensiones que circulan en los párrafos sueltos de un diálogo. La efusividad de Bolaño tiene mucho que ver, me parece, con el momento histórico en que está escribiendo, con la particular manera que tiene de concebirse al interior de un grupo ("los escritores latinoamericanos"). Piglia, acostumbrado a ser un autor secreto, se aleja siempre que puede de las comparaciones y los discípulos. Por eso resulta curiosa la profusión de artículos que insisten en equipararlos, en designar a uno como continuidad del otro. El diálogo que aquí nos ocupa no se desarrolla en ese sentido. Todo lo contrario. Por eso quise escribir un texto para discutirlo.

\section{Latinoamérica/La ex-tradición}

¿Usted es chileno, español o mexicano?

Soy latinoamericano.

Roberto Bolaño. Entre paréntesis.

Volvamos al momento preciso del diálogo que estamos rastreando ahora. Otra grieta se abre. Al decir "lo que suele llamarse latinoamericano se define por una suerte de anti-intelectualismo, que tiende a simplificarlo todo", Piglia hace, en primer lugar, un corte entre alta y baja cultura, gesto aristocrático que se acentúa si pensamos, en segundo lugar, que la obvia conclusión del diagnóstico del argentino es que para ser intelectual es preciso alejarse de "lo latinoamericano". No he olvidado que, al menos, también afirma que los libros de Bolaño son prueba de una resistencia a ese virus maligno. ¿Resistencia a qué? ¿Al color local? ¿A los malos autores? Son preguntas para otra discusión. ¿Qué le contesta Bolaño?

Sí, para nuestra desgracia, creo que seguimos siendo latinoamericanos. Es probable, y esto lo digo con tristeza, que el asumirse 
como latinoamericano obedezca a las mismas leyes que en la época de las guerras de independencia. Por un lado es una opción claramente política y por el otro, una opción claramente económica. (Bolaño, párr. 4)

Ser latinoamericano es un acto de fe y trae consigo una disposición solemne para la tragedia. Suelo fértil para quien desee escribirlo. La respuesta de Piglia es singular, porque ignora por completo las consideraciones del chileno y corre el eje hacia la visión que ciertos escritores (Hammet, W.H. Hudson, Lowry) han tenido sobre la cultura latina. Dice que está viviendo en California y que "aquí, por contraste, me siento un escritor digamos ítalo-argentino (un falso europeo, otro europeo exiliado)" (párr. 5). En "Conversación en Princeton", extensa entrevista de 1998 que cierra Crítica y ficción, estaba también esa reconstrucción del linaje personal: "Obviamente me siento mucho más cerca de John Berger o de Calvino que de García Márquez.” (223) Podemos sumar a este tipo de afirmaciones, por último, una idea que define el planteamiento central de Las tres vanguardias (2016):

Lo interesante es que este debate sobre el estado actual de las poéticas de la novela en Argentina se da en un momento en que, por fin, la literatura nacional no está en una relación asincrónica o de desajuste respecto del estado de la narrativa en cualquier otra lengua. Lo que hicieron Borges, Macedonio Fernández, Bioy Casares, Marechal o Cortázar fue muy importante para que esa situación de asincronía terminara. (14)

Sobra decir que esa situación asincrónica no tiene nada de positivo, según Piglia. Solo desde mediados del siglo XX, se puede colegir, la literatura argentina entra en la vanguardia y se equipara con el mundo. Vamos a detenernos un momento. Quiero, como corresponde, sustraerme por ahora a las opciones económicas y políticas para postular a la palabra "Latinoamérica", en el caso de Bolaño, y a "la ex-tradición", término acuñado por el mismo Piglia, como conceptos (ninguno de carácter unívoco o que se pueda aplicar a otros casos) esenciales para pensar el contacto entre dichos autores y la tradición. Para ello vamos a referirnos, por supuesto, al discurso de Borges "El escritor argentino y la tradición", en tanto que en él se entreveran ambas posturas. Insisto, 
no se trata de afirmar que hay un concepto asociado a la tradición con solo emitir la palabra "Latinoamérica"; son categorías fugaces apenas válidas para el campo simbólico que este ensayo construye.

La tradición de Bolaño es latinoamericana (si ustedes quieren, esta afirmación no se circunscribe a su trabajo con la poesía) porque de ella extrae todo lo que conforma su particular entramado narrativo. Si tenemos derecho a todas las tradiciones, como dice Borges, lo que Bolaño entiende por ello, esa toma de posesión, no pasa por establecer vínculos con la cultura polaca, irlandesa o judía, sino, en primera instancia, por desarrollar un estilo (y quien dice "estilo" habla siempre de su uso específico) que pretende constituirse en la lengua del continente americano. ¿Cuántos acentos, giros coloquiales, aparecen representados en Los detectives salvajes? No se trata simplemente de decir que Bolaño tiene un oído prodigioso, como él mismo hizo con Jaime Bayly. Más allá del alarde formal, hay una voluntad de hacer coincidir a esas diferentes voces, registros y situaciones como parte de un todo. Unificarlas. El drama que atraviesa Auxilio Lacouture en Amuleto funciona como sinécdoque de tantos otros similares (la Noche de los Lápices, el Cordobazo, la masacre de Tlatelolco, los atropellos a la comunidad universitaria peruana durante la dictadura de Odría, por ejemplo) para urdir, entonces, una experiencia colectiva, equiparable, que se extiende y repercute por cada país.

En segunda instancia podemos ir a sus discursos insufribles ("Derivas de la pesada", "Sevilla me mata" y "Los mitos de Chtulhu") para constatar, si fuese necesario, que allí no hay preocupación alguna por la sincronía de la literatura latinoamericana con el resto del globo. Hay una frase en "El misterio transparente de José Donoso", de Entre paréntesis (2004), que quizá sea apropiada para este punto: "Decir que él es el mejor novelista chileno del siglo es insultarlo. No creo que Donoso pretendiera tan poca cosa.” (100) ¿Qué pretende Bolaño? Está claro que eligió a América Latina (bajo la forma de sueño, tragedia o parodia) como su coto de caza privado. Los escritores que admira, los que injuria, sus breves incursiones en asuntos políticos, siempre provienen de ahí y hacia ese mismo lugar se dirigen. Incluso en España, donde sería plausible creerse "un falso europeo", Bolaño tiene claro su 
campo de operaciones e incluso parece justo decir que es por esa razón, por vivir ahí, que su voluntad tiene más fuerza. ¿Por qué va, digamos, al Encuentro de Escritores Latinoamericanos que organiza Seix Barral en 2003 en Sevilla cuando faltaba menos de un mes para su muerte? ¿Solo por el dinero? Va y lee "Los mitos de Chtulhu", según cuenta Ignacio Echevarría en la "Presentación" de Entre paréntesis, porque no había terminado "Sevilla me mata", un discurso inédito en el que dice, entre otros hallazgos, lo siguiente:

¿De dónde viene la nueva literatura latinoamericana? La respuesta es sencillísima. Viene del miedo. Viene del horrible (y en cierta forma bastante comprensible) miedo de trabajar en una oficina o vendiendo baratijas en el Paseo Ahumada. Viene del deseo de respetabilidad, que sólo encubre al miedo. (312)

Igual al discurso de Fernando Vallejo, con quien hace falta plantearle una simetría, la prédica fatalista de Bolaño es engañosa, porque encubre (si me disculpan) la esperanza de otro panorama. Todavía hay autores que saben entrar en la oscuridad con los ojos abiertos, que no buscan solo un ascenso social. Esa prédica, entonces, no está pensada para negar el valor o la importancia de la literatura latinoamericana. Más probable sería, y en esto también se parece a Vallejo, que no pueda evitar la crítica sobre lo único que le interesa. Si, como dijo alguna vez Alan Pauls en Página/12, Vallejo es "El último profanador", algo de ese apelativo se ajusta al chileno, en especial la frase que cierra dicho artículo: "Es decir, un hombre - quizás el último- con un altísimo sentido de lo sagrado." (Pauls párr. 8). Un hombre con un altísimo sentido del compromiso, podríamos decir. Bolaño pasa sus últimos días tratando de decir algo, no sobre sí mismo, sino sobre su oficio y el de otros, que lo sobrevivirán. Y ese acto gratuito tiene más fuerza, acaso por esa misma cualidad, que operaciones como 327 cuadernos (2015), el documental de Andrés Di Tella que muestra a un Piglia alicaído, casi irreconocible a causa de la esclerosis, pero dispuesto a dar la última puntada en el telar donde ha construido su mito de escritor.

Por otro lado, la ya mencionada "Conversación en Princeton" interroga la validez de la etiqueta "literatura latinoamericana" y propone un enfoque diferente: 
La literatura "latinoamericana" es un término que para mí está cada vez más puesto en cuestión, no porque nosotros no tengamos que trabajar con ese contexto y no porque no tengamos que enseñar esa tradición y esa cultura, que tiene obviamente mucha importancia histórica y política. (...) Cada vez más, creo que debemos apuntar a trabajar con áreas culturales y tradiciones localizadas. Quizá también debemos comenzar a distinguir el área del Caribe, el Río de la Plata o la región andina, etc., y no trabajar con un criterio tan amplio en el que todas las tradiciones se van a entreverar de una manera relativamente homogénea. (Crítica 221)

Está claro que, al menos en lo que respecta a este debate, Piglia es mucho más moderno, tal vez porque, ya lo sabemos, se ha sincronizado con el estado de la literatura en otras regiones, lo que explica su interés por desmarcarse de la generalización, que es un sello característico del Bolaño orador/ensayista. De cualquier manera, no es éste el asunto a señalar respecto al manejo que el argentino hace del concepto "tradición". En su notable artículo titulado "Ricardo Piglia y Roberto Bolaño: tradición y narratividad”, Andrea Torres Perdigón ha observado que:

La poética de Piglia y las formas literarias que valora dentro de la tradición son las que considera distantes y contrarias a la buena escritura o al esteticismo. Para él, el elemento determinante en su concepción de la literatura y del canon pertenece al orden de la experimentación; de ahí la defensa de ciertas formas de escritura que se ejemplifican en Arlt o en Macedonio. Todos estos aspectos muestran que concibe la literatura como una práctica que debe mantenerse libre y reformularse, repensarse siempre frente a la norma, frente a un canon que empieza a funcionar como normativo respecto a lo que es o no es considerado literario. (33)

Por supuesto, estoy de acuerdo con lo que afirma este párrafo y, en general, con las premisas de Torres Perdigón. No obstante, quisiera acercarme a un asunto en particular: ¿a qué se refiere Piglia cuando habla de "tradición"? Soy consciente de la existencia de una buena cantidad de trabajos que analizan de una forma u otra este tema, central en la escritura del argentino. Trataré de no repetir los juicios más 
conocidos al respecto. Mi interés, aquí, consiste en rastrear, sin ningún afán exhaustivo, dos de las diferentes definiciones que Piglia ofrece de dicho término a lo largo de los años hasta llegar a "La ex-tradición", ensayo publicado en formato libro por primera vez en la Antología personal (2014).

Una que considero importante (también porque menciona a "El escritor argentino y la tradición") aparece en "La novela polaca", conferencia perteneciente a Formas breves (2000). Tenemos una cita definitiva, que el autor escribe, en apariencia, sobre Borges y Gombrowicz, pero en realidad le sirve para definir a la perfección su propio método de trabajo:

Pueblos de frontera, que se manejan entre dos historias, en dos tiempos y a menudo en dos lenguas. Una cultura nacional dispersa y fracturada, en tensión con una tradición dominante de alta cultura extranjera. Para Borges (como para Gombrowicz) este lugar incierto permite un uso específico de la herencia cultural: los mecanismos de falsificación, la tentación del robo, la traducción como plagio, la mezcla, la combinación de registros, el entrevero de filiaciones. Esa sería la tradición argentina.

Y cuando digo tradición, quiero decir la gran tradición: la historia de los estilos. (Formas, 73)

En primer lugar, vemos que sí existiría una utilidad respecto a esa desincronización que se deplora en Las tres vanguardias. El movimiento en la periferia autoriza un ejercicio más incisivo de la escritura, en el orden de la experimentación, como dice Torres Perdigón. De inmediato pensamos en la primera novela de Bolaño que alcanza cierto reconocimiento: La literatura nazi en América, donde aparece toda la serie de operaciones que señala la cita anterior. Influencias ex-céntricas, por fuera del circuito hegemónico del siglo XX: las Vidas imaginarias de Schwob e Historia universal de la infamia, de Borges. "Entrevero de filiaciones" en toda regla, sí. Pero también una indecisión calculada respecto al tipo de libro que se presenta al lector, y aquí es posible trazar un paralelo con Prisión perpetua (1988): ¿es una enciclopedia?, ¿es un diario?, ¿cuál es la voz que enuncia? A partir de esta cita se puede deducir que cada literatura tendría una tradición privada, ¿no?, 
y que la tradición es, antes que una serie de nombres, una serie de procedimientos, un arte de la poética. El lugar desde donde se puede escribir, por desgracia o fortuna, es inescindible del contexto inicial. Y aquí quisiera señalar un corte decisivo, una frase de Borges que Piglia pasa deliberadamente por alto y a partir de la cual (de su omisión) se activa una serie de implicaciones profundas en su literatura. En "El escritor argentino y la tradición" se nos dice, tras el pasaje sobre la cultura judía e irlandesa, que:

Creo que los argentinos, los sudamericanos en general, estamos en una situación análoga: podemos manejar todos los temas europeos, manejarlos sin supersticiones, con una irreverencia que puede tener, y ya tiene, consecuencias afortunadas. (Discusión 161, la cursiva es mía)

Habría que repetirlo: "Los sudamericanos en general". Los sudamericanos en general. Piglia pervierte y transforma un texto fundacional para sus propios intereses, para la producción de su gloria. Borges considera que, en tanto provienen de naciones emergentes con una buena cantidad de semejanzas, la situación de estos escritores es homogénea. Justo contra lo que se pronuncia Piglia, que defiende la especificidad de la literatura argentina y al que no le conviene, vamos a decir, que estos procedimientos sean tomados por otras regiones. ¿Cuál es la tradición chilena? Leyendo a Bolaño se podría concluir que es bastante parecida a la argentina. Nada de esto, está claro, es reconocido por Piglia, quien dirá, en una entrevista virtual de 2010 con los lectores de El País español, respecto al chileno: "Admiro sobre todo la energía de sus libros." (párr. 92) Sutiles mecanismos de defensa, furtivas pugnas por el control de una forma particular de escritura.

Pero es en "La ex-tradición" donde Piglia lleva al límite su relectura del precedente sentado por el famoso discurso de Borges, porque vuelve a definir, siempre con el énfasis marcado en su propia experiencia de narrador, lo que significa decir "tradición" y a asignarle unos usos específicos que, sobra mencionarlo, él mismo ya ha transitado. Leamos, pues, una cita más: 
Para un escritor la memoria es la tradición. Una memoria impersonal, hecha de citas, donde se hablan todas las lenguas; los fragmentos y los tonos de otras escrituras vuelven como recuerdos personales; con más nitidez, a veces, que los recuerdos vividos. (...) Son imágenes entreveradas en el fluir de la vida, una música inolvidable que ha quedado marcada en la lengua. La tradición tiene la estructura de un sueño: restos perdidos que reaparecen, máscaras inciertas que encierran rostros queridos. Escribir es un intento inútil de olvidar lo que está escrito. Por eso en literatura los robos son como los recuerdos: nunca del todo deliberados, nunca demasiado inocentes. Las relaciones de propiedad están excluidas del lenguaje: podemos usar todas las palabras como si fueran nuestras, hacerles decir lo que queremos decir, a condición de saber que otros en ese mismo momento las están usando quizás del mismo modo. (Antología 147)

Difícil no leer lo anterior sin verlo como una respuesta oblicua al caso del Premio Planeta 1997. Un contrato está por fuera del lenguaje; una demanda equivale a un exabrupto. Se retoman ahí, también, los puntos básicos que identifican a la tradición argentina: el robo, las falsas atribuciones, la multiplicidad de filiaciones. Aparece, por otro lado, un concepto nuevo: la tradición se usa cuando ha sido olvidada por otros:

Podemos definir a la tradición como la prehistoria contemporánea, como el residuo de un pasado cristalizado que se filtra en el presente. En este sentido un escritor es como el rastreador del Facundo, busca en la tierra el rastro perdido, encuentra el rumbo en las huellas confusas que han quedado en la llanura. Siempre se trabaja con la tradición cuando no está. Un escritor trabaja en el presente con los rastros de una tradición perdida. Un escritor trabaja con la ex-tradición. Por un lado lo que ha sido, la historia anterior, casi olvidada, y por otro lado la obligación semijuridicial de ser llevado a la frontera. O traído a ella: siempre por la fuerza. La extradición supone una relación forzada con un país extranjero pero también con el propio país. (...) La figura de la extradición es la patria del escritor, del que construye los enigmas, del que intriga y trama un complot. Obligado siempre a recordar una tradición perdida, forzado a cruzar la frontera. Así se funda la identidad de una cultura. Al menos esa ha sido la obsesión de la literatura argentina desde su origen. (Antología 148) 
Se trata entonces de exhumar restos perdidos y traerlos al presente. De escribir una obra experimental a partir de precedentes que nadie recuerda. El aviso que persiste, la etiqueta "literatura argentina" como marca, irónicamente, de la propiedad, frontera inviolable. Ahí donde Bolaño abre posibilidades, Piglia clausura senderos. Los miembros de una élite auto designada, ese "nosotros" fantasmal que lo ha elegido como vocero, ¿saben adentrarse en la oscuridad con los ojos abiertos? Esta no es una pregunta retórica.

\section{El mecenas/Una voz en el vacío}

El primer significado del paso de la literatura al cine es el dinero, literalmente y en todos los sentidos.

Ricardo Piglia. Crítica y ficción.

Este último apartado se ocupa, siempre de manera fragmentaria, de las relaciones entre dinero, poder y propiedad que están concentradas en un pasaje del diálogo Bolaño-Piglia fechado en 2001. Para ello se emplearán algunas entrevistas realizadas a cada autor y, de forma particular, los ensayos "La solución Bolaño", de Alan Pauls, incluido en la compilación Bolaño salvaje (2008) a cargo de Gustavo Faverón Patriau y Edmundo Paz Soldán, así como "La figura de escritor en Bolaño”, escrito por Ricardo Gutiérrez-Mouat y publicado en el número 29, correspondiente a octubre de 2015, de la revista chilena Dossier. Hemos citado pocas escenas, sólo las esenciales, de este diálogo que nos ocupa como pretexto, como trasunto, como metáfora. En realidad, lo que sigue al fragmento sobre Latinoamérica no es memorable (menciones a incontables autores, Piglia con los argentinos que desea imponer, Bolaño que le responde siempre con un mexicano para contrapuntear), salvo por un momento -que, por lo demás, se repite en otros contextos- de honestidad brutal a cargo de Piglia. En el medio de una charla anodina sobre los traductores y su importancia, aparece esta propuesta:

Tendríamos que hacer alguna vez una Enciclopedia Biográfica de Traductores Inmortales (e invisibles), ¿no sería sensacional? (...) 
una lista de oscuros personajes extraordinarios, escritores asalariados que escriben a tantos centavos por palabra, los únicos verdaderos profesionales de la literatura, los nuevos folletinistas, que viven dedicados a la literatura, pero como escritores clandestinos, mal vistos y mal pagados, los verdaderos malditos, siempre postergados, siempre ausentes, y que por eso mismo serán quizá los grandes creadores del futuro. (...) Tendríamos que conseguir un mecenas y dedicarnos a preparar esa enciclopedia infinita. Estoy seguro de que nos haría inmortales, y sería no sólo un acto de justicia sino una revelación y una versión cómica de la por sí cómica historia de la literatura. (Conversación párr. 9, la cursiva es mía)

Bolaño rápidamente se desmarca de semejante ofrecimiento y cambia el tema de conversación. Ahora bien, eso no quiere decir que haya ignorado el comentario de Piglia, al que alude de manera oblicua al menos en dos ocasiones futuras. La columna titulada "Intento de agotar a los mecenas" pertenece, según la cronología que presenta Entre paréntesis, a una fecha desconocida entre mayo de 1999 y julio de 2001 (vale anotar que dicho texto es el último dentro de este periodo de tiempo, lo que podría indicar que es, en efecto, posterior al diálogo con Piglia). Así comienza:

Nunca tuve un mecenas. Nunca nadie me conectó con nadie para hacerme beneficiario de una beca. Nunca ningún gobierno ni ninguna institución me ofreció dinero, ni ningún caballero elegante se sacó la chequera delante mío, ni ninguna señora trémula (de pasión por la literatura) me invitó a tomar el té y se comprometió a pagarme una comida diaria. (Entre 193)

Sigue una hilarante descripción de los tipos de mecenas que existen (la abuelita melancólica, el familiar, el cuarentón homosexual, los agregados culturales) y un cierre que insta al lector a reconocer algo sobre lo que Bolaño insiste a menudo: la naturaleza tortuosa y necesariamente solitaria del trabajo literario:

Detrás de esta muchedumbre, sin embargo, se esconde el único, el verdadero mecenas. Si uno tiene la suficiente paciencia como para llegar hasta allí, tal vez lo pueda ver. Y si lo ve probablemente acabe 
defraudado. No es el diablo. No es el estado. No es un niño mágico. Es el vacío. (Entre 195)

¿El vacío o su amenaza? Se escribe, entonces, para huir del vacío, para tapiarlo de alguna manera. ¿Cuál sería el mecenas por el que Piglia pedía? Uno imagina que los profesores latinoamericanos que trabajan en universidades de Estados Unidos, a quienes Bolaño equipara con Stalin, sustentados "... en la fuerza bruta y en una cobardía sin fin." (Entre, 195). ¿Podemos ignorar que el mismo Piglia es un profesor latinoamericano (un falso europeo) en una universidad norteamericana cuando el diálogo tiene lugar? Quiero señalar también las implicaciones del primer párrafo de dicho texto. Decir "Nunca tuve..." se apoya, evidentemente, en el presente del escritor, como si dijera "He logrado estos premios sin necesidad de...". Es una historia de éxito, de redención, pero con principios. Es cierto, no es posible saber (al menos en este momento) con seguridad cuál es la fecha de publicación del "Intento de agotar a los mecenas", pero creo que su lugar en relación con el diálogo Piglia-Bolaño suena ominoso de cualquier forma, si sucedió antes o después. Después, decíamos, el texto se convierte en una alusión secreta, a la espera de los lectores que rastreen sus huellas. Antes viene a ser un acto de prestidigitación, otro ejemplo de la manera en que la literatura se adelanta a la realidad. De cualquier forma, me parece, es extraordinario.

El segundo texto es "Derivas de la pesada". Ahí está el famoso pasaje en el que Bolaño se burla del "desvarío" que Piglia teje con respecto a Arlt. Cuestiona, por ejemplo, la imagen (su verosimilitud) con la que se abre "Un cadáver sobre la ciudad", de Formas breves, elogia y ataca al mismo tiempo a ambos autores:

Pero en cualquier caso es Piglia quien eleva a Arlt dentro de su propio ataúd, sobrevolando Buenos Aires, en una imagen muy pigliana o muy arltiana, pero que, en rigor, sólo sucede en la imaginación de Piglia y no en la realidad. (...) Con esto no quiero decir que Arlt sea un mal escritor, al contrario, es buenísimo, ni tampoco pretendo decir que Piglia lo sea, al contrario. Piglia me parece uno de los mejore narradores actuales de Latinoamérica. Lo que pasa es que se me hace difícil soportar el desvarío -un desvarío gangsteril, de la pesada- que Piglia tiende alrededor de Arlt, probablemente, el único inocente en este asunto. (Entre 27) 
¿En qué radica ese “desvarío gangsteril”? ¿Cuál sería la escuela imposible que predica Piglia? ¿Por qué no puede tener discípulos? Algunos críticos, como Andrea Torres Perdigón (en su artículo ya citado), han creído ver en las palabras de Bolaño un problema básico de forma:

Ahora bien, este desacuerdo entre Bolaño y Piglia es un ejemplo nítido de sus concepciones de la literatura. Para el autor chileno esa escritura fuera de la norma y de cierta corrección del estilo que representaría Arlt no puede ser la única tradición o el punto a partir del cual se escribe (...) Hay algo en esa escritura que Bolaño percibe como antiproductivo o incluso destructivo, y este punto es llamativo. (Tradición 34)

Aunque reconozco que esa es una respuesta plausible, me interesa retomar la última frase de esta cita. ¿Qué es lo destructivo de Arlt y, por extensión, de Piglia? Quizá el pasaje sobre los mecenas y la inmortalidad ofrezca una señal al respecto. Dicho sea de paso, en un obituario escrito a la muerte del chileno, Rodrigo Fresán recuerda unas palabras que éste le habría enviado por correo electrónico:

Yo no sé cómo hay escritores que aún creen en la inmortalidad literaria. Entiendo que haya quienes creen en la inmortalidad del alma, incluso puedo entender a los que creen en el Paraíso y el Infierno y en esa estación intermedia y sobrecogedora que es el Purgatorio, pero cuando escucho a un escritor hablar de la inmortalidad de determinadas obras literarias me dan ganas de abofetearlo. (párr. 10)

Lo interesante, otra vez, es que no podamos saber la fecha de esta reflexión. Hemos establecido cuál es la reacción de Bolaño, según sus propias palabras, ante los elementos centrales de la propuesta de Piglia (conseguir un mecenas, alcanzar la inmortalidad). Pero existe otro, que puede conectarse con Arlt, y que está en las antípodas del proyecto narrativo (y ético) de Bolaño: el dinero. No es muy aventurado decir que Arlt y Piglia son dos de los grandes escritores del dinero en la literatura latinoamericana. El dinero del mecenas para escribir la Gran Enciclopedia, el dinero que llenará las arcas al venderse tal obra magna. En "La figura de escritor en Bolaño", Ricardo Gutiérrez-Mouat dice que 
los años de carencia que pasa el chileno en Barcelona ayudan a definir su imagen (vagabundo, desposeído, trovador) y rescata un poema, "El dinero", en el que se recuentan unas exiguas ganancias empleadas en unas cintas para grabar a músicos de jazz y en un bistec de cerdo. Cosas útiles, nada ostentosas. Hay que oponer esta construcción al Piglia de Nombre falso, para nombrar solo uno, que paga sumas altísimas por textos originales de Roberto Arlt y, ante la posibilidad de una estafa, amenaza con demandar a quien se los ha vendido.

Ese es un corte que está también en la textura del diálogo y, a su manera, en cada uno de los temas aquí discutidos. El Bolaño que trabajó en un camping, hijo de un boxeador devenido camionero y una maestra de escuela, no puede coincidir con las ofertas que le hace Piglia, perteneciente a la aristocracia intelectual latinoamericana en Estados Unidos. Si aún quedara espacio, sería el momento de recordar lo que el argentino le responde al periodista Maximiliano Seitz tras ganar el Premio Planeta 1997: "Voy a usar el dinero para escribir tranquilo durante uno o dos años. Claro que también tendré que responder a mis acreedores... Y, si me alcanza, tal vez hasta arregle el techo de mi casa..." (Seitz, párr. 11) y compararlo con las respuestas de Bolaño a la entrevista de Mónica Maristain en Entre paréntesis:

¿Por qué no tiene aire acondicionado en su estudio?

-Porque mi lema no es Et in Arcadia ego, sino Et in Esparta ego. (...)

¿Qué cosas compró con el dinero que ganó en el Rómulo Gallegos?

-No muchas. Una maleta, según creo recordar. (331-334)

Entre esas dos tensiones transcurre una historia de la literatura latinoamericana contemporánea. Piglia hace aparecer siempre una relación económica en lo que está escribiendo y en eso es absolutamente arltiano (la fiebre del oro que se narra en Respiración artificial, los herederos inquietos al acecho de la muerte del senador Ossorio, los gritos espantados del público uruguayo que ve en su televisor cómo los malandras argentinos queman la plata que han robado, la intriga básica de Blanco nocturno, la moneda con la que el narrador le paga a Russell, el fotógrafo, por permitirle ver su modelo a escala de Buenos Aires en el 
prólogo de El último lector y lo que significa que éste se la devuelva al salir, por ejemplo). La política de una transacción, contra la que Bolaño se posiciona, es precisamente la línea que atraviesa al argentino como escritor, como figura pública y como inventor de Emilio Renzi. Son las condiciones particulares de cada experiencia las que ayudan a definir la figura construida. No es lo mismo ir de repente, como Bolaño, from rags to riches, a trabajar décadas en diferentes espacios del campo cultural (editor, docente, conferencista, etc.) sin alcanzar en mucho tiempo ese raro efecto simultáneo del aplauso crítico y la solvencia económica.

En "La solución Bolaño", Alan Pauls resume este conflicto al identificar una filosofía (si ustedes quieren): la "Vida Artística" que se detiene ahí donde Piglia parece seguir hacia adelante y viceversa:

Porque la Vida Artística según Bolaño no es un medio, no es un pretexto: no se vive artísticamente para producir una obra ni para ser alguien, tampoco para fundar y defender una identidad o fabricarse una imagen: la obra, el personaje -Belano, Lima, Cesárea Tinajero, incluso el mismo Bolaño- pueden estar o no, pueden ser pálidos o brillantes, memorables o fallidos, pero son siempre efectos de la vida, sus pliegues aleatorios -nunca su origen y menos su fundamento. La Vida Artística es un principio de inmanencia, una especie de campo informe, anti jerárquico, sin más allá, que lo procesa todo -política, sexualidad, socialidad, territorio- y se define menos por lo que son las cosas que por lo que pueden, menos por valores que por potencias. (Bolaño salvaje 329)

Por eso es un error creer, a partir del epígrafe inicial, que Bolaño desconoce que Piglia también trabaja a Witold Gombrowicz. Sabemos que el chileno ha leído Formas breves; de hecho, es "La novela polaca", el texto sobre dicho escritor que ahí se incluye, la referencia con la que inicia el diálogo entre ambos. Bolaño habla de enamoramientos, de pasión, y con eso quizá se refiera a una decisión vital. ¿Por qué Piglia, vamos a reformular, no quiso seguir el proyecto de Gombrowicz? Ese plan imperturbable que él mismo ha condensado en "El escritor como lector", cuya escena central cuenta que el polaco rechaza la posibilidad de ser publicado (y el inmediato "refugio económico" que esto supone) porque el editor no se compromete a publicar también el Diario argentino. ¿Por qué Piglia no tiene la paciencia, la altivez 
que tuvo Gombrowicz ante las tentaciones? En el fondo eso es lo que pide Bolaño a los escritores latinoamericanos: pudor, sacrificio. Que resistan los cantos de sirena del Estado y las editoriales todo lo que les sea posible. Que lean a Borges otra vez. Aquello que en Piglia, a poco que uno lo estudie, suena a producción y pretexto es, en Bolaño, potencia, efectos plenos. Con esto no quiero decir, como no quería, supuestamente, éste, que uno es mejor que el otro, o viceversa. Hablo de decisiones éticas que trascienden la especificidad del oficio literario. De contradicciones y pequeñas estafas sobreimpresas en la escritura de cada uno. De un problema irresoluble alrededor del que es posible construir un modelo lector. ¿Qué sucede si voy a escribir sobre estos autores y no tengo en cuenta esta discusión, en la que acaso yo mismo me veo representado? ¿Cuál será mi respuesta al enigma? Por lo pronto, este ejercicio sugiere una línea de trabajo imprecisa, zigzagueante, pero siempre visible. Ese vaivén entre ambas orillas que atraen y aterran de manera simultánea es, para el nosotros anónimo al que cada crítico aspira a dirigirse, un lujo y un exceso.

\section{Conclusión}

Quizá un punto de encuentro en el medio de tantas distancias sea el interés de ambos autores por la ciencia ficción. En el prólogo de su Antología personal, Piglia recuerda la película Total recall (1990) de Paul Verhoeven y observa que su tema es “... la memoria artificial y los recuerdos ajenos.” (11), relación que de alguna manera está presente en todo el género. Me gusta pensar, entonces, a muchos de los puntos que he tratado de ofrecer aquí para debates futuros bajo esa luz. ¿La figura de escritor no equivale, después de todo, a construir una serie de sofisticados recuerdos artificiales? Desde el relato "Sensini" hasta las anécdotas que Piglia contará hacia el final de su vida sobre un posible encuentro con Borges en la estación de trenes de Adrogué, el pasado apócrifo se filtra y amenaza con deslizarse a la realidad de las biografías oficiales. El título de este artículo hace referencia al problema del mecenas que sintetiza la marcada oposición que percibo en el diálogo Bolaño-Piglia, un problema por lo demás ilusorio, dicho en condicional. ¿Qué quiere decir un sueño que tiene la forma de una pesadilla para 
Bolaño y de un anhelo casi fantástico para Piglia? ¿Podemos pensarlo, partiendo de esa diferencia, como un elemento que ayuda a leer sendas obras? Todo parece indicar que sí. La falta de un mecenas, un padrino, es una sombra que se proyecta sobre estos escritores del siglo XX, ambos provenientes de la clase media, sin un pasado cultural (un familiar acaudalado, el vago relumbre de un linaje) que los legitime de entrada. De hecho, el relato fundacional que empiezan a construir desde cero y que conforma cada figura surge, podríamos decir, como respuesta a dicha carencia. Sería ingenuo creer que esto no sale reflejado en la obra escrita, o que no se puede encontrar en discursos, entrevistas, diálogos: los lugares donde el escritor actualiza constantemente la forma en que desea ser leído y, al tiempo, en los que deja ver sombras de otra voz que el público desconoce.

El personaje del intelectual decadente, con proyectos inconclusos y promesas grandilocuentes que no sabrá cumplir, aparece constantemente en el trabajo de estos autores, lo que podría deberse a la tradición instalada por Borges desde "Pierre Menard, autor del Quijote". Los poemas que nunca se citan de Arturo Belano y Ulises Lima en Los detectives salvajes, la olvidable primera novela de Renzi, descrita en Respiración artificial, su lugar subalterno muchos años y novelas después ante la imponente Ida Brown de El camino de Ida, el enjuto Belano (o Bolaño) que subsistirá en el exilio gracias a su papel en el ajusticiamiento de Carlos Ramírez Hoffman/Wieder en La literatura nazi en América y en Estrella distante, son pequeños ejemplos de una tensión que no se resuelve en el plano ficcional y que alcanza su punto de quiebre en el diálogo comentado. Como suele ocurrir con la literatura, dicho diálogo cifra en la figura del mecenas la densa trama narrativa y privada que acompaña tanto a Bolaño como a Piglia en ese momento de 2001. También como en un sueño, entonces, esa figura no es apenas ella misma sino que se usa para hablar de otros asuntos: Latinoamérica, la posición del escritor ante el poder y el dinero, su mirada atemorizada u optimista del trabajo propio y del que hacen los contemporáneos. La memoria artificial, que también fascina y repele al Deckard de Blade runner (1982), tiene la propiedad de parecer personal cuando en realidad es colectiva. Invito al lector accidental, si me es posible, 
a leer estas páginas con el ánimo confuso de ese momento que está a medio camino entre la inconsciencia y la vigilia, entre la introspección y los ojos abiertos. Un momento pleno de significados que siempre parece a punto de revelar una verdad hasta la interrupción que implica despertarse, aturdido, como quien viene de un recuerdo ajeno.

\section{Referencias}

Bolaño, Roberto. Amuleto. Barcelona: Editorial Anagrama. 1999. Impreso.

Bolaño, Roberto. El gaucho insufrible. Barcelona: Editorial Anagrama. 2003. Impreso.

Bolaño, Roberto. Entre paréntesis. Barcelona: Editorial Anagrama. 2004. Impreso.

Borges, Jorge Luis. "El escritor argentino y la tradición". Cátedra latinoamericana Julio Cortázar. Web. 17 Agosto 2019. http://www.jcortazar. udg.mx/sites/default/files/JL\%20Borges\%20Discusiones.pdf

Fresán, Rodrigo. "Roberto Bolaño (1953-2003)". Letras libres. Digital. 14 Agosto 2019. https://www.letraslibres.com/mexico/robertobolano-1953-2003

Garcés, Gonzalo. "La autobiografía de Bolaño.” Letras.mysite. Digital. 10 Agosto 2019. http://www.letras.mysite.com/rb011004.htm

Gutiérrez Mouat, Ricardo. "La figura de escritor en Bolaño". Dossier. Digital. 12 Agosto 2019. http://www.revistadossier.cl/la-figura-del-escritor-enbolanol

Pauls, Alan. "El último profanador." Página/12. Digital. 13 Agosto 2019. https:// www.pagina12.com.ar/diario/suplementos/libros/10-3602-2009-11-08. $\underline{\mathrm{html}}$

Paz Soldán, Edmundo y Gustavo Faverón Patriau. Bolaño salvaje. Barcelona: Editorial Candaya. 2008. Impreso.

Piglia, Ricardo y Roberto Bolaño. "Conversación entre Ricardo Piglia y Roberto Bolaño". Archivo Bolaño. Digital. 10 Agosto 2019. https:// garciamadero.blogspot.com/2012/06/conversacion-entre-ricardo-piglia-y. $\underline{\mathrm{html}}$

Piglia, Ricardo. Antología personal. México: Fondo de Cultura Económica. 2014. Impreso.

Piglia, Ricardo. Crítica y ficción. Barcelona: Editorial Anagrama. 2001. Impreso.

Piglia, Ricardo. Formas breves. Barcelona: Editorial Anagrama. 2000. Impreso.

Piglia, Ricardo. Las tres vanguardias: Saer, Puig, Walsh. Buenos Aires: Eterna Cadencia Editora. 2016. Impreso. 
Piglia, Ricardo. Los diarios de Emilio Renzi: los años felices. Barcelona: Editorial Anagrama. 2016. Impreso.

Piglia, Ricardo. Por un relato futuro: conversaciones con Juan José Saer. Barcelona: Editorial Anagrama. 2015. Impreso.

Piglia, Ricardo. "Borges, por Piglia - Clase 1". YouTube. Digital. 10 Agosto 2019. https://www.youtube.com/watch? $v=\mathrm{m} 3$ htEzn1BIc

Sánchez, Matilde. "Ricardo Piglia: "Su prosa tiene la energía de la generación beat"'. Clarín. Digital. 28 Octubre 2017. https://www.clarin.com/home/ entrevista-narrador-ricardo-piglia-50-anos-rayuela-julio-cortazar_0_ H1Xfun8jDQg.html

Seitz, Maximiliano. "Para Piglia, la distinción es un refugio económico". La Nación. Digital. 5 Octubre 2017. https://www.lanacion.com.ar/sociedad/ para-piglia-la-distincion-es-un-refugio-economico-nid80238

Sarlo, Beatriz. "Ficciones del saber". Escritos sobre literatura argentina. Buenos Aires: Siglo XXI Editores Argentina. 2007. Impreso.

Torres Perdigón, Andrea. "Ricardo Piglia y Roberto Bolaño: tradición y narratividad". Perifrasis. 6. Julio-Diciembre 2012: 23-41. Digital. 29 Mayo 2017. http://www.scielo.org.co/pdf/peri/v3n6/v3n6a02.pdf

Volpi, Jorge. "Tercera consideración. América Latina, holograma". El insomnio de Bolivar: cuatro consideraciones intempestivas sobre América Latina en el siglo XXI. Colombia: Random House Mondadori. 2009. Impreso. 